\title{
RESEARCH
}

\section{Getting physicians to accept new information technology: insights from case studies}

\author{
Liette Lapointe, Suzanne Rivard
}

$\infty \quad$ See related article page $\mathrm{I}_{5} 83$

\section{ABSTRACT}

Background: The success or failure of a computer information system (CIS) depends on whether physicians accept or resist its implementation. Using case studies, we analyzed the implementation of such systems in 3 hospitals to understand better the dynamics of physicians' resistance to CIS implementation.

Methods: We selected cases to maximize variation while allowing comparison of CIS implementations. Data were collected from observations, documentation and interviews, the last being the main source of data. Interviewees comprised 15 physicians, 14 nurses and 14 system implementers. Transcripts were produced; 45 segments of the transcripts were coded by several judges, with an appropriate level of intercoder reliability. We conducted within-case and crosscase analyses of the data.

Results: Initially, most staff were neutral or enthusiastic about the CIS implementations. During implementation, the level of resistance varied and in 2 instances became great enough to lead to major disruptions and system withdrawal. Implementers' responses to physicians' resistance behaviours played a critical role. In one case, the responses were supportive and addressed the issues related to the real object of resistance; the severity of resistance decreased, and the CIS implementation was ultimately successful. In the other 2 cases, the implementers' responses reinforced the resistance behaviours. Three types of responses had such an effect in these cases: implementers' lack of response to resistance behaviours, antagonistic responses, and supportive responses aimed at the wrong object of resistance.

Interpretation: The 3 cases we analyzed showed the importance of the roles played by implementers and users in determining the outcomes of a CIS implementation.

CMAJ 2006;I74(II):1573-8

7 he potential contribution of a clinical information system (CIS) to the quality of health care ${ }^{1-3}$ is generally acknowledged, and numerous hospitals have been engaged in their implementation. ${ }^{4-6}$ Investment in information technology (IT) in the health care sector is higher than ever. ${ }^{7}$ In the United States, hospital IT spending was
$\$ 25.8$ billion in 2004 and is expected to increase to $\$ 30.5$ billion in $2006 .^{8}$ However, only a handful of CIS implementations have been successful. ${ }^{7,9}$

Physicians play a critical role in the success of CIS implementation, ${ }^{10-13}$ but many are reluctant to use IT tools. ${ }^{14,15}$ Rather than viewing resistance as a barrier to be removed, ${ }^{16}$ or taking for granted that resistance will be dysfunctional and even destructive, ${ }^{17}$ we considered that it can also be useful in preventing the implementation of systems that are flawed ${ }^{18}$ or that would have negative organizational impacts. ${ }^{17}$ We analyzed cases of CIS implementation in 3 hospitals to understand better the dynamics of physicians' resistance to CIS implementation. We also sought to determine whether resistance was an a priori reaction or whether it developed only later, during the implementation.

\section{Methods}

For our analytical framework, we drew from a model that suggests that, when a CIS is introduced, resistance behaviours occur if users perceive threats from the interaction of initial conditions and system features. ${ }^{12}$ During implementation, triggers may change the nature of the initial conditions or change the object of resistance, and resistance behaviours may vary in intensity, from apathy to aggressive actions (Appendix I). ${ }^{12}$

For our study, we selected 3 hospitals in which CIS had been or was being implemented. The cases were selected with enough similarities and differences so as to maximize variation and allow for comparison (Table I). ${ }^{19,20}$

For data collection, we used direct observation, documentation and interviews, with interviews being the principal source of data. The initial people interviewed were the project manager, the nursing director and the medical director at each hospital. A snowball sampling strategy ${ }^{21,22}$ was then used, whereby those interviewed identified additional people whom they thought held critical information about the project, had exhibited extreme behaviours of acceptance or resistance, or portrayed the typical behaviours of their professional group. Data collection ended when information obtained from additional respondents could not be justified in terms of effort and resources. ${ }^{23}$ We used open-ended questions and asked respondents to describe the implementation, from project initiation to termination. Following an interview protocol, additional questions were prompted to ensure data completeness 
Table 1: Features of case studies used in analysis of computer information system (CIS) implementations at 3 hospitals

\begin{tabular}{|c|c|c|c|c|}
\hline Case & $\begin{array}{c}\text { Type } \\
\text { of hospital }\end{array}$ & $\begin{array}{l}\text { CIS software } \\
\text { package* }\end{array}$ & $\begin{array}{c}\text { Outcome of } \\
\text { implementation }\end{array}$ & $\begin{array}{l}\text { No. of people } \\
\text { interviewed } \\
\text { for analysis }\end{array}$ \\
\hline 1 & Community & Alpha & Failure & $\begin{array}{l}\text { Physicians: } 7 \\
\text { Nurses: } 4 \\
\text { Implementers: } 4\end{array}$ \\
\hline 2 & University & Alpha & Success & $\begin{array}{l}\text { Physicians: } 4 \\
\text { Nurses: } 4 \\
\text { Implementers: } 5\end{array}$ \\
\hline 3 & University & Delta & Failure & $\begin{array}{l}\text { Physicians: } 4 \\
\text { Nurses: } 6 \\
\text { Implementers: } 4\end{array}$ \\
\hline
\end{tabular}

*The names and manufacturers of the systems are not provided to protect the anonymity of the hospitals. †Implementers included the head of physicians, the head of nursing, the chief executive officer and the project manager at each site.

and comparability. Interviews lasted one hour on average. Data gathered through observation and documentation were used to validate and complement the interview data.

Transcripts were produced and coded with the use of QSR NUD`IST (Scolari, Sage Publications, Thousand Oaks, Calif). Forty-five segments of the transcripts were coded by several judges; intercoder reliability was found to be adequate. Data were analyzed in 2 stages. ${ }^{24,25}$ First, within-case analysis provided a rich understanding of each case. Second, common patterns were revealed through cross-case analysis.

\section{Results}

The analysis of CIS implementation at the 3 hospitals revealed the dynamics of resistance in each case.

\section{Case 1}

\section{Prologue}

CIS implementation was planned at a new community hospital. At the time of staff recruitment, all nurses and physicians were informed that they would be using the CIS. A multidisciplinary committee of physicians, nurses and other professionals was formed to evaluate available systems and identify the one best suited to meet the hospital's needs. After an exhaustive review, the committee selected Alpha (the real name of the system has been withheld to protect the anonymity of the hospital). The implementers (the head of physicians, the head of nursing, the hospital's chief executive officer [CEO] and the project manager), invited physician department heads as well as some nurses and clinicians to try the system. To promote the system, they also created committees to encourage the participation and involvement of the users.

\section{Resistance unfolds}

With the system's introduction 2 years later, the principal tool in medical practice, the paper file, was replaced with a computer monitor. Use of the CPOE (computer physician order entry) module for test requisitions and results represented a major change in the interface between physicians and patient files. The system not only affected work methods, it also required that physicians spend more time - up to I. 5 to 2 hours every day - managing patient records. Although the doctors put little effort into learning how to use the system, the implementers decided to continue with the project as scheduled.

Eighteen months later, a second module, the computerized care plan, was added for documenting prescriptions for care and treatment. Previously, physicians usually prescribed care and treatment by giving oral instructions to nurses. With the new computerized module, prescriptions had to be entered into the system only by physicians. Several doctors refused to do so. They asked nurses to perform the treatments, and some were told "No, I won't remove [an IV or a catheter] unless you prescribe it" or "No, I won't [take a blood sample or check vital signs] unless you prescribe it" (physician 6). During these interactions, the object of resistance changed from the system's features to the system's significance as physicians started to feel that the system was undermining their relationship with the nurses. Although physicians reacted to this change at first by voicing their personal indignation, they then united and informed the hospital's CEO that they could not accept such a situation. The implementers chose not to intervene at this point and asked the physicians to try to be more cooperative.

In the following months, physicians' complaints escalated. When physicians demanded the system's withdrawal, the implementers stated that the project would continue as scheduled and told the physicians to continue using the system while attempts were made to modify some features. The hospital's board of directors decreed that 6 physicians who refused to use the system be denied the right to admit patients. At this point, the system's implementers became the object of resistance. The physicians' power vis-à-vis the hospital's administration was threatened; they reacted aggressively, threatening to terminate their association with the hospital.

\section{Epilogue}

Some doctors resigned. Those who remained asked their professional association for assistance. As a result of the resignations, the emergency department could no longer function, and concerns arose that the hospital might have to close. The provincial ministry of health intervened, dismissed the CEO and put the hospital under trusteeship. The CIS was dramatically downsized, with a mere $25 \%$ of its functionality remaining operational (Fig. I). 


\section{Case 2}

\section{Prologue}

CIS implementation was planned at a university hospital where all of the health care professionals, including physicians and residents, saw the new system as a way to prepare for the 2ist century. The implementers (the head of physicians, the head of nursing, the hospital CEO, a physician project manager and another, non-physician project manager) agreed to a common implementation strategy. A multidisciplinary committee, including physicians, nurses and other health care professionals, was formed to review the systems available on the market. As in case I, the Alpha system was chosen. The first steps in the implementation process included promotional and training activities that targeted primarily physicians and nurses.

\section{Resistance unfolds}

The first module that was introduced handled admissions, transfers and discharges. It was soon followed by a CPOE module for test requisitions and results. Most physicians initially adopted the system without any major incidents. Some seemed

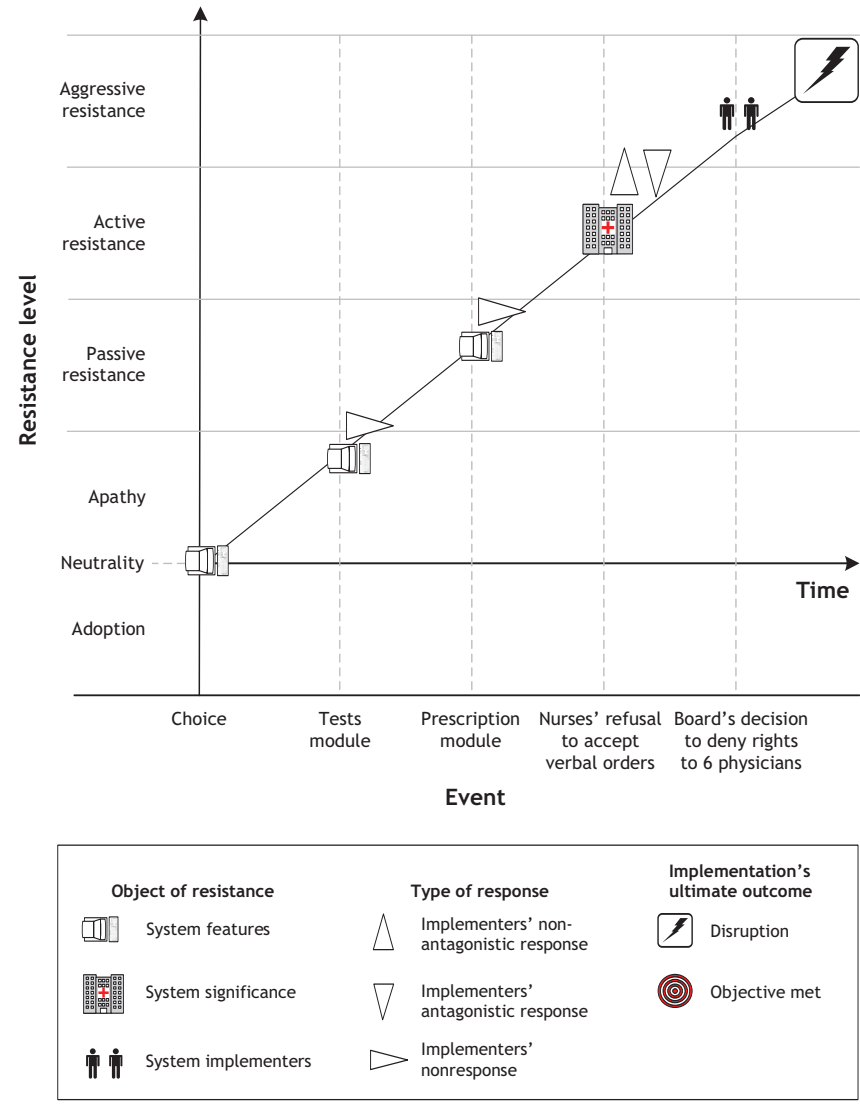

Fig. 1: Case 1: Evolution of resistance behaviours during implementation of computer information system (CIS) in community hospital. more reluctant than others to use the system; their respective department head met with each of them and reiterated the importance of the project. Other physicians reacted through humour. An example involved requests for radiographs. Formerly, one requested a radiograph by completing a form. With the CIS, the first item on the electronic form to justify the request was "bullet wound." Because the hospital served a small community where such injuries would rarely occur, one physician responded to what he saw as the ridiculous prominence of "bullet wound" by checking it off as the justification for every radiograph request. In response, the physician responsible for the CIS implementation sent the physician a referral for a psychiatric consultation. That ended the story.

When the pharmacy module was introduced a few months later, it was quickly perceived as an inefficient way to prescribe medications. The physicians considered the system a threat to patient safety and their ability to deliver quality care. The residents sent a letter to management in which they requested among other things the withdrawal of the pharmacy module. They stated that they would return their keys to the system, which would have meant a return to paper files.

\section{Epilogue}

The hospital administration took the residents' requests for changes into consideration and responded wherever possible. As a result, the schedule of system implementation was relaxed and the pharmacy module withdrawn so that necessary improvements could be made. Four years after the start of the implementation process, all parties were using the system, and the project was considered a success (Fig. 2).

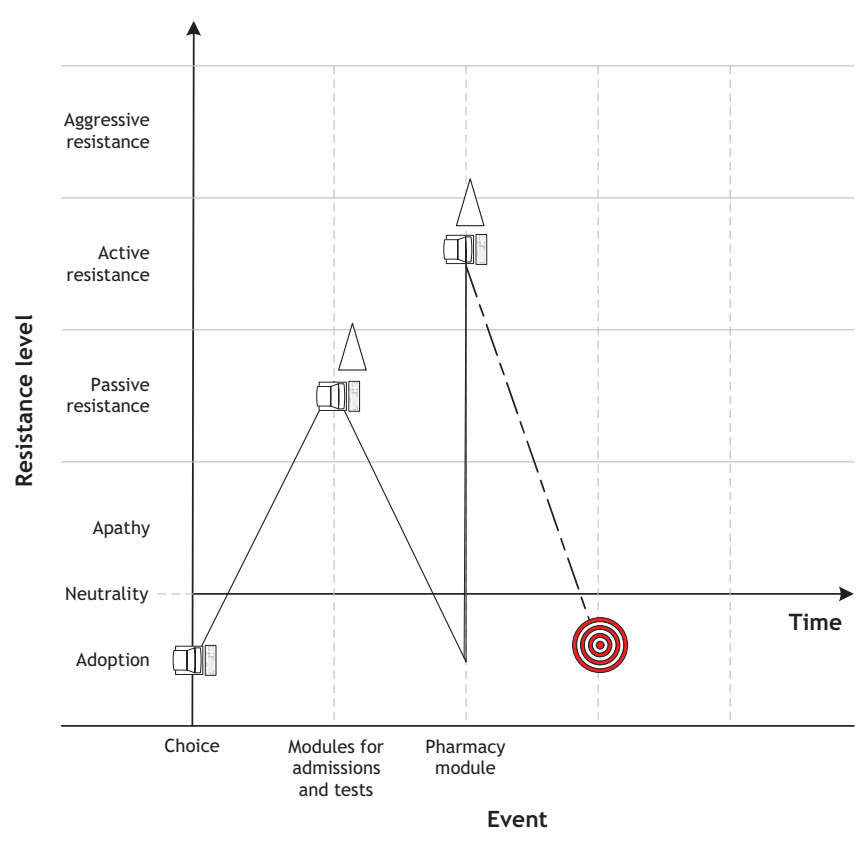

Fig. 2: Case 2: Evolution of resistance behaviours during $\mathrm{CIS}$ implementation in a university hospital. See Fig. 1 for explanation of symbols. 


\section{Case 3}

\section{Prologue}

This case involved a university hospital. Once the decision was made to acquire a CIS, a multidisciplinary selection committee was formed. The committee assessed several systems and chose Delta (the real name of the system has been withheld to protect the anonymity of the hospital). The medical staff, especially on the surgery units, were enthusiastic about the idea of getting a computerized system. To keep up the momentum, the implementers (the head of physicians, the head of nursing, the hospital CEO and the project manager) created a medical committee and organized training sessions. They chose the surgery units to be the pilot sites because all of the surgeons and residents had a positive attitude toward the system and had participated enthusiastically in the training sessions.

\section{Resistance unfolds}

Despite their initial enthusiasm, when the CPOE module for test requisitions and results was implemented, the surgeons quickly developed reservations about how well the system met their needs. Entering prescriptions was tedious and timeconsuming. The surgeons and the residents complained forcefully about the system's complexity and the fact that it had resulted in abrupt changes in their work habits. The implementers did not respond to these complaints.

The physicians' dissatisfaction with the computer system stirred up pre-existing conflicts with the nurses and resulted

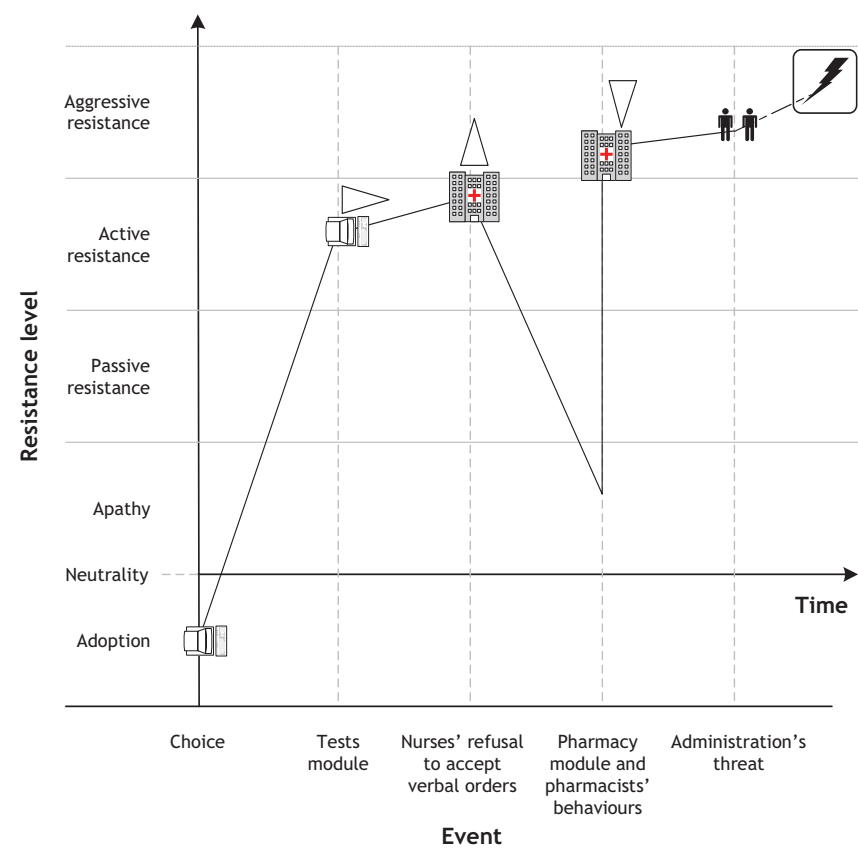

Fig. 3: Case 3: Evolution of resistance behaviours during CIS implementation in a university hospital. See Fig. 1 for explanation of symbols. in new confrontations between the 2 groups. The physicians felt as if they were doing nurses' work, because the prescription data they had to enter were used to create nursing care plans. The nurses refused to enter orders when asked by the physicians. Heated discussions occasionally ensued. In an attempt to find a peaceful solution and satisfy the physicians, the implementers asked nurses to enter data for the surgeons and even appointed a full-time nurse for the task.

Although this solution brought peace for a while, the use of the newly introduced pharmacy module brought unorthodox prescription procedures to the attention of the pharmacists, who reacted by insisting that the rules be followed to the letter. The module's introduction raised the issue of the entire process by which professional responsibility is exercised by physicians and pharmacists, and the latter group wanted to take control of the process of prescribing and distributing medications. This request increased resistance among the surgeons. The surgeons chose a representative to discuss the issue with the hospital's CEO. Eight months after the introduction of the system, the representative demanded that the CIS be withdrawn.

The administration responded to the demand with a threat: if the surgeons refused to use the system, beds that had been allocated to them would be given to physicians with a more positive attitude toward the system. The surgeons rebelled as a group, explicitly asking their colleagues in other care units not to admit patients to any beds that became available in this way.

\section{Epilogue}

The other physicians supported the surgeons by refusing to admit patients into surgery units. With beds sitting idle, the administration decided, less than a year after system implementation, to withdraw the CIS from the surgical units (Fig. 3).

\section{Cross-case analysis}

Our within-case analysis showed that the object of resistance can change as resistance unfolds and that the level and severity of resistance behaviours can vary during system implementation. In the cross-case analysis, we examined the influence of implementers' responses on physicians' resistance behaviours.

The cases showed that the level of resistance can vary during a CIS implementation: it continually increased in case I, whereas it fluctuated in both cases 2 and 3 . Cases I and 3 showed that resistance at times reached such a level that it disrupted the organization and led to CIS withdrawal. Case 2 illustrated how acceptance followed several episodes of resistance. How was this possible? Control may explain these observations. Although successfully exercised in case 2, control was only partially successful in case 3 (until the implementation of the pharmacy module), and not at all in case $\mathrm{I}$.

In case 2, the implementers responded to the physicians' reluctance to use the CIS in a supportive fashion and, with an ironic response to practical jokes, directly addressed the issues related to the real object of resistance. Similarly, in case 
3, when the object of physicians' resistance was the system's significance, the implementers responded to complaints by asking nurses to enter data for the surgeons and even appointed a full-time nurse for the task.

Other responses from implementers reinforced physicians' resistance behaviours and ultimately led to disruption. Three types of responses had such an effect. The first, observed in cases I and 3, was the implementers' nonresponse to the physicians' resistance behaviours, which was followed by increased levels of resistance. The second type was an antagonistic response, such as that in cases I and 3 when the main resisters were denied the right to admit patients, which led to organizational disruptions. Finally, even supportive responses, when aimed at the wrong object, reinforced resistance; this was the situation in case $\mathrm{I}$, in which the implementers made modifications to system features in response to complaints related to the system's significance.

\section{Interpretation}

Our study focused on cases of CIS implementation in hospitals where physicians represented the focal group. To further validate the model, it would be instructive to see how, in similar settings, the resistance of other groups (e.g., nurses) evolve. Also, the model's external validity would be improved by studying CIS implementation in different settings.

We found that, although staff may be enthusiastic about a CIS implementation, the dynamics of resistance during the implementation may lead to system rejection. The 3 cases we analyzed showed the importance of the roles played by implementers and users in determining the outcomes of a system implementation. In particular, antagonistic responses from implementers to users' resistance behaviours appear to have reinforced these behaviours. When resistance was ignored, there were similarly pernicious effects. Moreover, even when implementers' reactions were supportive of users, targeting the wrong object of resistance led resisters to remain oblivious to any proposed improvement. The study also suggests, however, that implementers are not the only ones accountable for explaining resistance behaviours, their origins and consequences. Physicians, as users, cannot afford to retreat into a belligerent position or engage in a dynamic that causes a potentially useful CIS to become a pawn in a power struggle. They ought to recognize the object of their resistance and modulate their behaviours accordingly.

These results are in line with those of previous studies of the implementation of information systems in hospital settings. First, although numerous studies have reported that CIS use translates into benefits (e.g., fewer medication errors, ${ }^{26-29}$ increased financial gain, ${ }^{30}$ better quality of care, ${ }^{31,32}$ improved practitioners' performance, ${ }^{33-35}$ enhancement of diagnostic accuracy ${ }^{36}$ and increased safety ${ }^{3,37}$ ), computer systems that satisfy users and that actually contribute to the quality and safety of patient care are rare..$^{4-6,38-42}$ By depicting the dynamics of the implementation process, our study helps to explain why this is so. Second, previous research has shown that, although a system's technical factors (e.g., it "fits the workflow," augments physicians' judgment rather than re- places it, ${ }^{43}$ is user friendly, is flexible $e^{38,44,45}$ and has an innovative design ${ }^{45,46}$ ) may be crucial in determining the success or failure of a CIS implementation, organizational factors (e.g., supportive leadership and championship, ${ }^{38,43,44,46,47}$ clinician involvement $t^{47}$ and physician empowerment ${ }^{38}$ ) are paramount. Our study examined the dynamics between 2 major stakeholders in CIS implementation - users and implementers and showed how critical a factor it can be in the outcome of an implementation.

A number of lessons can be learned from the cases in our study. If the object of resistance is the computer system itself and when the system is seen to impair productivity or threaten quality of care, physicians have a responsibility to bring this to the attention of the hospital's administration so that problems can be fixed. However, if the object of resistance is the system's significance, the real targets are often the organization of work and political issues between groups of users. The CIS implementation may be revealing pre-existing problems. In these cases, users and implementers should engage in introspection, evaluate their roles in these problems and look beyond modifications to the system for solutions. Finally, if the implementers are the object of resistance, the computer system becomes extraneous to the problem. There is then a high risk that users will enter a spiralling trajectory of resistance caused by political struggles that will lead to disruption and even system abandonment. In these instances, physician resistance is costly and can negatively affect quality of care.

\section{This article has been peer reviewed.}

From the Faculty of Management, McGill University (Lapointe), and HEC Montréal (Rivard), Montréal, Que.

\section{Competing interests: None declared.}

Contributors: Both authors contributed substantially to the conception and design of the study, and the acquisition, analysis and interpretation of the data. Both drafted the article, reviewed it for important intellectual content and gave final approval of the version to be published.

Acknowledgement: This research was supported by grants from the Social Sciences and Humanities Research Council of Canada and Québec's Fonds concerté d'aide à la recherche.

\section{REFERENCES}

I. Bennett JW, Glasziou PP. Computerised reminders and feedback in medication management: a systematic review of randomised controlled trials. Med J Aust 2003;178:217-22.

2. Kinn JW, Marek JC, O'Toole MF, et al. Effectiveness of the electronic medical record in improving the management of hypertension. J Clin Hypertens 2002;4:415-9.

3. Bates DW, Gawade AA. Improving safety with information technology. N Engl Med 2003;348:2526-34.

4. Morrisey J. Harmonic divergence. Cedars-Sinai joins others in holding off on CPOE. Mod Healthc 2004;34:I6.

5. Southon FCG, Sauer C, Dampney CNG. Information technology in complex health service: organizational impediments to successful technology transfer and diffusion. J Am Med Inform Assoc 1997;4:112-24.

6. Powell G. Microchips versus stethoscopes, part 2: revisiting OSCAR at the Foothills Hospital. CMAJ I996;155(II):I6oI-3

7. Berner ES, Detmer DE, Simborg D. Will the wave finally break? A brief view of the adoption of electronic medical records in the United States. J Am Med Inform Assoc 2005;12:3-7.

8. Mullaney TJ, Weintraub A. The digital hospital: how info tech saves lives and money at one medical center. Is this the future of health care? Bus Week 2005;Mar 28:77-84

9. Haugh R. Wiring docs - Overcoming legal and financial hurdles is crucial if hospitals and physicians are to link patient data. Hosp Health Netw 2004;78:44-8.

Io. Geyer S. Physicians: the key to IT success. Trustee 2004;57:6-1o. 
II. Loomis GA, Ryes JS, Saywell RM Jr, et al. If electronic medical records are so great, why aren't family physicians using them? J Fam Pract 2002;51:636-4I.

12. Lapointe L, Rivard S. A multilevel model of resistance to information technology implementation. MIS Quarterly 2005;29(3):46I-9I

I3. The no-computer virus. Economist 2005;30:65-7.

I4. Ash JS, Bates DW. Factors and forces affecting EHR system adoption: report of 2004 ACMI discussion. J Am Med Inform Assoc 2005; 12:8-12.

I5. Poon EG, Blumenthal G, Jaggi T, et al. Overcoming barriers to adopting and implementing computerized physician order entry systems in US hospitals. Health Aff 2004;23:184-90.

I6. Kossek EE, Young W, Gash DC, et al. Waiting for innovation in the human resources department: Godot implements a human resource information system. Hum Resour Manage 1994;33:135-6o.

I7. Markus ML. Power, politics, and MIS implementation. Commun ACM 1983;26: 430-44.

I8. Joshi K. A model of users' perspective on change: the case of information systems technology implementation. MIS Quarterly I99I;15:229-40.

19. Yin RK. Case study research, design and methods. 3rd ed. Newbury Park (CA) Sage; 2003.

20. Guba EG, Lincoln YS. Fourth generation evaluation. Newbury Park (CA): Sage; I989.

2I. Crabtree BF, Miller WL. Doing qualitative research. Vol 3 in: Research methods for primary care. Newbury Park (CA): Sage; 1992.

22. Patton MQ. Qualitative research and evaluation methods. 3 rd ed. Thousand Oaks (CA): Sage; 2002.

23. Lincoln YS, Guba EG. Naturalistic inquiry. Newbury Park (CA): Sage; I985. p. 233.

24. Langley A. Strategies for theorizing from process data. Acad Manage Rev I999;24: 69I-7Io.

25. Eisenhardt KM. Strategies for theorizing from process data. Acad Manage Rev I989;I4:532-50.

26. Berger RG, Kichak JP. Computerized physician order entry: Helpful or harmful? J Am Med Inform Assoc 2004; II:100-3.

27. Kaushal R, Shojania K, Bates DW. Effects of computerized physician order entry and clinical decision support systems on medication safety. Arch Intern Med 2003 I63:I409-I6.

28. Bates DW, Teich JM, Lee J, et al. The impact of computerized physician order entry on medication error prevention. J Am Med Inform Assoc 1999;6:313-21.

29. Bates DW, Leape L, Cullen DJ, et al. Effect of computerized physician order entry and team intervention on prevention of serious medication errors. JAMA I998;280:13 II-6.

30. Wang SJ, Middleton B, Prosser LA, et al. A cost-benefit analysis of electronic medical records in primary care. Am JMed 2003;114:397-403.

3I. Gandhi TK, Sequist TD, Poon EG, et al. Primary care clinician attitudes towards electronic clinical reminders and clinical practice guidelines. AIMA Annu Symp Proc 2003:848
32. Kuperman GJ, Teich JM, Tanasijevic MJ, et al. Improving response to critical laboratory results with automation: results of a randomized controlled trial. $J \mathrm{Am} \mathrm{Med}$ Inform Assoc 1999;6:512-22.

33. Garg AX, Adhikari NKJ, MacDonald $\mathrm{H}$, et al. Effects of computerized clinical decision support systems on practitioner performance and patient outcomes: a systematic review. JAMA 2005;293:1223-38.

34. Schuster DM, Hall SE, Couse CB, et al. Involving users in the implementation of an imaging order entry system. J Am Med Inform Assoc 2003;IO:3I5-2I.

35. Hunt DL, Haynes RB, Hanna SE, et al. Effects of computer-based clinical decision support systems on physician performance and patient outcomes: a systematic review. JAMA I998;280:1339-46.

36. Friedman CP, Elstein AS, Wolf FM, et al. Enhancement of clinician's diagnostic reasoning by computer-based consultation: a multisite study of 2 systems. JAMA I999;282:I85I-6.

37. Bates DW, Cohen M, Leape LL, et al. Reducing the frequency of errors in medicine using information technology. J Am Med Inform Assoc 200I;8:299-308.

38. Chin T. Doctors pull plug on paperless system. Am Med News 2003;46:I-3.

39. Benko LB. Back to the drawing board. Modern Healthcare 2003;33(4):12.

40. Wears RL, Berg M. Computer technology and clinical work, still waiting for Godot. JAMA 2005;293:126I-3.

4I. Kaushal R, Barker KN, Bates DW. How can information technology improve patient safety and reduce medication errors in children's health care? Arch Pediat Adolesc Med 2001;155:1002-7.

42. Southon G, Sauer C, Dampney K. Lessons from failed information systems initiative: issue for complex organisations. Int J Med Inform I999;55:33-46.

43. Garibaldi RA. Computers and quality of care - a clinician's perspective. $N$ Engl Med ig98;338:259-6o.

44. Ash JS, Gorman PN, Seshadri V. Computerized physician order entry in US hospitals: results of a 2002 survey. J Am Med Inform Assoc 2004;II:95-9.

45. McDonald CJ, Overhage JM, Tierney WM, et al. The Regenstrief medical record system: a quarter century experience. Int J Med Inform I999;54:225-53.

46. Teich JM, Glaser JP, Beckley RF, et al. The Brigham integrated computing system (BICS): advanced clinical systems in an academic hospital environment. Int J Med Inform 1999;54:197-208.

47. Doolan DF, Bates DW, James BC. The use of computer for clinical care: a case series of advanced US sites. J Am Med Inform Assoc 2003;10:94-I07.

Correspondence to: Dr. Liette Lapointe, Faculty of Management McGill University, IooI Sherbrooke St. W, Montreal QC $\mathrm{H}_{3} \mathrm{~A}_{\mathrm{I}} \mathrm{G}_{5}$; fax 514 398-3876; liette.lapointe@mcgill.ca

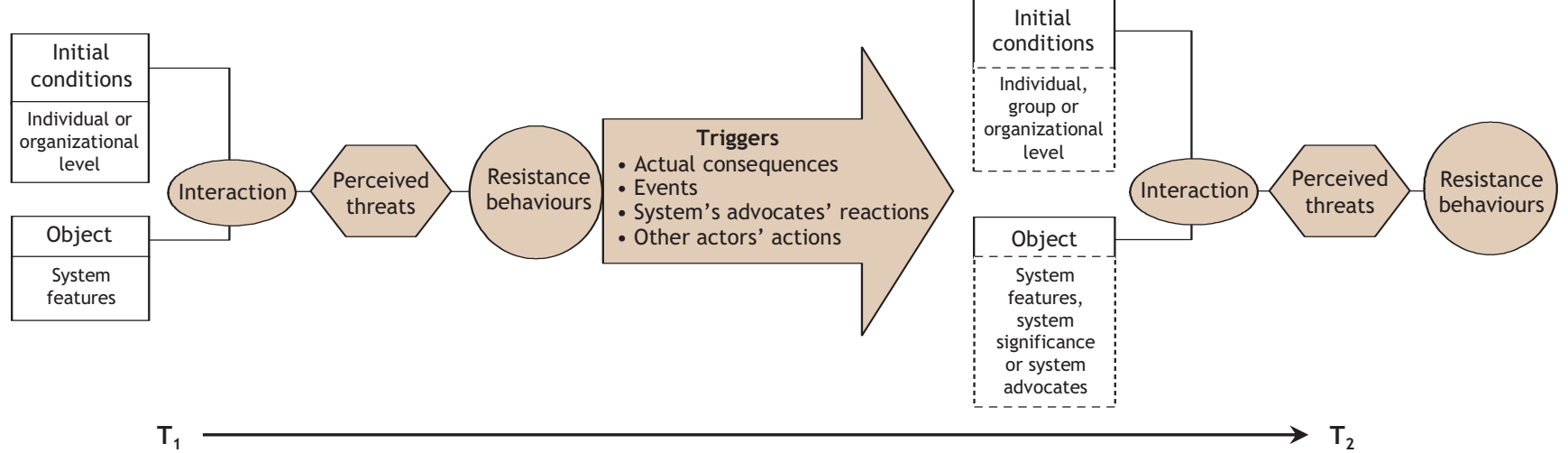

Appendix 1: Model of multilevel resistance to information technology (IT) implementation. At time $\mathrm{T}_{\text {, }}$, when a computer information system (CIS) is introduced, resistance behaviours will result if a subject perceives threats from the interaction between the system's features and initial conditions at the individual or organizational level. Consequences of CIS use and non-use, whether or not they were foreseen, will occur. These consequences and possibly other triggers may modify the set of initial conditions. The new set will become the initial conditions at time $\mathrm{T}_{2}$. If a trigger affects an initial condition involving the balance of power between the group and other user groups, it also changes the object of resistance from the system to the system significance. If the relevant initial conditions pertain to the power of the resisting group vis-à-vis the system implementers, the object of resistance is also modified from the system significance to the system implementers. Again, at time $\mathrm{T}_{2}$, resistance behaviours will follow if threats are perceived from the interaction between the object of resistance and the initial conditions. Reprinted with permission from Lapointe and Rivard." 